\title{
The Effects of Hypertext Structure, Presentation, and Instruction Types on Perceived Disorientation and Recall Performances
}

\author{
Banu Cangoz \& Arif Altun \\ Hacettepe University, Turkey
}

\begin{abstract}
Navigation in web-based environments is one of the challenging tasks for hypertext readers. During reading, hypertext readers are reported to allocate their cognitive resources to meet the cognitive demands and are often reported to get disoriented while navigating through hyperlinks. Meanwhile, readers' understanding of hypertext structures and memories interact while navigating between pages. Yet, as researchers pointed out and the correlations are taken into account, there are no research studies that have directly explored their factorial patterns within the context of hypertext reading process. Therefore, the purpose of this study is both to investigate the confirmatory study of a Perceived Disorientation Scale (PDS), and to investigate the effects of hypertext structure, presentation type, and instruction type on readers' implicit and explicit memory performances and their perceived disorientation. Instruction type and presentation type main effects were found to be significant only on WSC scores (memory scores). However, there was no significant main effect of hypertext structure observed for neither WSC nor PDS-TR scores. The interaction effect between hypertext structure and presentation type was significant only on PDS-TR scores, yet no other interaction effects were significant. Potential implications of these results for e-learning providers and content developers in hypertext are discussed, followed with further research questions.
\end{abstract}

Keywords: Disorientation; Hypertext navigation; Hypertext reading; Implicit memory; Explicit memory

\section{Introduction}

Web environment, with its social (cyberspace) and cognitive (hyperspace) dimensions (Boechler, 2001), is represented by the space metaphor where readers navigate along with links in hypertext. Although some researchers question the relevance of such capabilities to learning (e.g., Dillon, 2000; Dillon \& Gabbard, 1998), they agree on the fact that orientation is one of the most difficult navigational problems users face in hypertext (McDonald \& Stevenson, 1998). While navigating in hypertext, readers are reported to experience certain cognitive barriers, among which is disorientation. These cognitive barriers are reported to keep them away from successful navigation both when recalling, searching, constructing mental representations (Cress \& Knabel, 2003) as well as learning from hypertexts (e.g., Amadieu et al., 2009). 
Hypertext refers to a system with a non-sequential (non-linear), electronic, multimedia, and hypermedia, which creates an interactive and flexible environment where reading is contingent upon computers by linking multiple sources of information. This flexibility lets users make their own decisions to navigate among the provided links. Navigation in such an environment appears to be configured as a series of cognitive processes (Gamberini \& Bussolon, 2001) and readers carry out certain cognitive, navigational, and informational tasks (see Kim \& Hirtle, 1995 for more details).

It has been well-documented that hypertext readers often get disoriented (e.g., Nielsen, 1990; Shapiro \& Niederhauser, 2004). Disorientation can be defined as the mental state of feeling lost when navigating in hypertext systems. According to Conklin (1987), disorientation is a psychological state resulting from problems in constructing pathways across a hypertext. The indications of disorientation based on the self-reported research data show that users (1) do not know where to go next; (2) know where to go but not how to get there; and (3) do not know where they are in relation to the overall structure of the document (Edwards \& Hardman, 1989). Consequently, they may become frustrated, lose interest, and experience a measurable decline in efficiency (McDonald \& Steveson, 1998). It is, therefore, important to quest how different hypertext structures, presentation types, and instructions affect and/or change readers' perceived disorientation and memories.

In a broader context, there are two distinct structures in hypertext: Hierarchical and networked structures. In hierarchical structures, readers are provided contextual cues with organizational links; whereas in networked structure, readers are provided relational links. In either of these structures, links could be presented in various modalities (types), among which are verbal and pictorial links.

\section{Theoretical Framework}

\section{Hypertext Structure and Perceived Disorientation While Reading From Hypertext}

Hypertext structure refers to how information is structured and presented to readers. The most common categorizations are hierarchical and network structures. In hierarchical structure, information is clustered in nodes, and readers are provided links to navigate between those nodes in a hierarchical manner. In networked structure, however, no hierarchy exists and readers can navigate through links without a need to follow any hierarchical steps. During navigation, especially in networked structure, readers' prior experience (e.g., Rouet \& Levonen, 1996), prior knowledge (Amadieu et al., 2009), and their schema about networked hypertext structure (Altun, 2000) are among the reported causes for readers' disorientation in hypertext environments.

Altun (2000) examined experienced computer users' perception of disorientation from a qualitative paradigm during hypertext reading in structured and networked hypertext environments. This study reported that regardless of hypertext structure and readers' expertise on computer use, readers felt disoriented while reading. Altun (2003) further concluded that not only novice computer users felt disorientation, also expert computer users experienced disorientation in hypertext environments. 
In a recent study, Amadieu et al. (2009) explored the effects of prior knowledge (high prior knowledge vs. Low prior knowledge) and concept-map structure (hierarchical vs. network) on disorientation, cognitive load, and learning from networked documents with 24 adults. As far as disorientation is concerned, LPK learners experienced higher disorientation during learning with the networked structure concept map than the hierarchical structure concept map, whereas no differential effect of concept-map structure was found for high prior knowledge learners. Amadieu et al. (2009) also used eye tracking data to gain more insights about readers' navigational behaviors. Based on eye tracking data analysis, the researchers further concluded that since learners were not obliged to return to a concept map, but go on to deeper levels at each node. Thus, learners were more open to experience disorientation in networked hypertext environments.

\section{Implicit / Explicit Memory Types and Perceived Disorientation}

Memory consists of several functionally separate subsystems, among which are explicit and implicit memories. Implicit memory requires unintentional recall of earlier encounters; whereas, explicit memory refers to recalling them consciously and with certain intent (Graf \& Schacter, 1985; Schacter, 1987). Automatic processes are known to require less attention with unconscious efforts; whereas controlled processes are conscious and require more cognitive effort and attention (Light, Prull, La Voie, \& Healy, 2000). Research findings support the classification of memory as implicit and explicit not only by providing theoretical but also by providing anatomical foundations (Markowitch, 2000; Yasuno et al., 2000).

In hypertext environments, implicit memory (memory without the conscious awareness of the original event that caused it) during navigation can help in directing attention to the target more efficiently, whereas explicit memories can help in finding the target, which are based on implicit memories (Oulasvirta, Kärkkäinen \& Laarni, 2005).

In their recent review of 38 hypertext reading research studies, DeStefano and LeFevre (2007) evaluated the predictions of the process of hypertext reading model comparing the versions of hypertexts. They concluded that working memory capacity mediated the impact of hypertext features. In other words, readers with low working memory were usually disadvantaged in hypertext. Moreover, they further reported that hierarchical structures yielded better results in favor of low prior knowledge readers and consistent with that of the knowledge domain. In another study, Amadeieu et al. (2009) deductively argued that highly structural hypertext provides high coherence, which leads to better text-based recall than low coherent hypertext. These results indicate that memory and hypertext structures seem to be correlated when readers are requested to complete explicitly articulated reading tasks. Yet, it is not clear how presentation and instruction types would interfere with the hypertext reading process.

Another variable in understanding memories in navigation was the nature of tasks. In a research study, Rouet (2003) assessed the effects of task complexity during searching and learning from a hierarchically organized hypertext. Rouet (2003) reported that the experiment did not show a strong effect of background knowledge on students' document search strategy, and the students achieved a greater level of incidental learning when working on contents representative of their area of study. 
Oulasvirta (2004) explored the information finding tasks with printed web pages in two conditions: Navigation-orientation and content-orientation with 24 participants. The results indicated that the locations and features of task-relevant and task-irrelevant elements are remembered distinctly. In other words, it was found that navigation-orientation leads to better feature memory for navigation elements than for content elements, and to a better overall feature memory for the page than content-orientation.

Oulasvirta (2004) concluded with a caution that navigation leads to encoding that is more accessible in situations cued by directly observable information and it was more difficult for navigation-oriented users to verbalize and recollect contents of their memory, whereas their recognition accuracy could be on the same level or even better than in content orientation.

In their research, Oulasvirta, Kärkkäinen and Laarni (2005) explored the strategies in identifying a link from a web page whether users either rely on expectation of prototypical locations or on memories of earlier visits to the page. They concluded that attention was guided by implicit expectations regardless of conscious awareness and beliefs of locations of links are consciously accessible. Moreover, they reported that deep processing is required for memories to become consciously accessible.

When these studies are taken together, it can be concluded that hypertext structures and related memories interact during hypertext reading while navigating between pages. Yet, (a) whether the structure of hypertext might interfere with reading process, and (b) how readers perceive disorientation in different instruction types (explicit and implicit) affect readers' disorientation and recall performances remains an unanswered question.

\section{Presentation Type and Perceived Disorientation}

Graphical representations are among the widely used components in e-learning environments. The use of these representations have been supported and rooted in the theory of multimedia learning that students learn better from text and pictures than from text alone (Mayer, 2001). Moreover, the use of pictures as graphical cues is a common practice to provide navigational guides for readers.

In their review of hypertext research, DeStefano and LeFevre (2007) reported that the increased demands of decision-making and visual processing in hypertext had impaired reading performance. This finding supports the fact that complex graphical overviews did not reliably enable learning and navigation, whereas navigational support from restricted access and visible link types were helpful. The researchers also draw attention to the fact that no studies have been reported to explore memory for information presented in various text formats. They go further to add that more research is needed to measure working memory and executive functions to identify the mental subsystems that are engaged in hypertext reading.

In the light of the literature above, in this study, the effects of hypertext structure, instruction type, and presentation type on readers' implicit and explicit memory performances and their perceived 
disorientation levels have been investigated. First, a confirmatory factor analysis has been applied to validate the Perceived Disorientation Scale (PDS) for the target language in order to determine readers' perceived disorientation levels. Second, it is explored whether hypertext structure (HS), instruction (IT) and presentation types (PT) affected readers' perceived disorientation levels and their implicit and explicit memory performances. In addition, readers' navigational data were analyzed to provide more in-depth information regarding their disorientation levels.

\section{Methodology}

\section{Design and Participants}

This study was designed as $2 \times 2 \times 2$ factorial design. The factors were HS (hierarchical vs. networked), IT (implicit vs. explicit) and PT (verbal vs. pictorial). The data have been collected from 80 volunteer adults (Female=36, Male=44) aged 19-26 ( $M=21.65, S D=1.44)$. First, prior to assigning them any reading task, all participants were administered the Visual-Aural Digit Span Test-Revised (VADS-B) in a silent computer laboratory at a university setting. VADS-B was used as a scanning tool to measure short-term memory capacity. VADS-B is a forward digit span test with four subtests measuring attention, concentration and short-term memory span. Each of these subscales is composed of eight digit spans, from two digits to nine digits. The four subtests are: Aural-Verbal (AV), Visual-Verbal (VV), Aural-Written (AW), and Visual-Written (VW). VADS-B total score is equal to the arithmetic total of scores achieved (longest digit span remembered) in each subtest. Accordingly, the lowest score is zero and the highest score is 36 in this test. VADS, developed by Koppitz (1977) and revised and varied (VADS-B) (Karakas \& Yalin, 1995), had already been subjected to adaptation, norm determination and standardization studies for target cultural background (13-54 age) (Karakas \& Yalin, 1995). The reported test-retest reliability is 0.84 and the correlation coefficient calculated with WAIS forward digit span test is 0.69 , and with WAIS backward digit span is 0.67 . Means and standard deviations of VADS-B total scores in different experimental conditions were shown in Table 1.

Secondly, participants were first rank ordered and then randomly assigned to eight groups of equal sizes (10 per group) based on their short term memory span capacity measured by VADS-B. Implicit and explicit memory manipulation was controlled by verbal instruction. In implicit memory condition, participants were not informed, but those in explicit memory condition group were informed that there would be a memory measurement upon finishing their reading task.

Table 1. Means and Standard Deviations of VADS-B Scores on Experimental Conditions

\begin{tabular}{lllll}
\hline & Hierarchical & & Networked & \\
\hline & Verbal & Pictorial & Verbal & Pictorial \\
\hline Implicit & $26.90(3.51)$ & $27.10(3.38)$ & $26.60(2.99)$ & $28.30(1.77)$ \\
& $(n=10)$ & $(n=10)$ & $(n=10)$ & $(n=10)$ \\
Explicit & $28.00(4.11)$ & $25.40(2.80)$ & $25.70(1.70)$ & $25.70(3.62)$ \\
& $(n=10)$ & $(n=10)$ & $(n=10)$ & $(n=10)$ \\
\hline
\end{tabular}




\section{Data Collection Tools}

\section{Word Stem Completion (WSC) Task}

Implicit and explicit memory performance is measured by the WSC task. The WSC task consisted of 50 word fragments for which only the first three letters were provided. In the dictionary of the target language, there exist at least three words beginning with the first three letters of these words. These words were selected from the most frequently used words in the Vocabulary Norms list prepared for the target culture (Tekcan \& Goz, 2005). The presentation of the word fragments for which participants were asked to complete within the scope of WSC task was performed as was done in the study stage. The mean number of letters in the two word list was equal and/or matched. The WSC task in which to complete a word stem composed of the first three words (e.g., word stem: TAB........, target word: TABLE). Hypertext font type (Arial) and size (12 point) in the study phase were same with WSC test form.

In the WSC task, under implicit instructions, participants were asked to complete the given letters to form the first word that pops up in their minds, whereas under explicit instructions, they were asked to complete the given letters to form the words presented in the study stage and to write them into the test form. The amount of correct word fragments completed during the test stage by the participants to any word previously presented at the study stage was taken as the dependent variable measure.

\section{Perceived Disorientation Scale-Turkish (PDS-TR)}

Original Perceived Disorientation Scale (PDS) has been developed to measure web users' perceived disorientation while navigating and validated by Ahuja and Webster (2001) with 300 university students. The scale had two factor structures (constructs to measure), which are named as ease of use and disorientation. The correlation between ease of use and disorientation factors are reported to be high $(r=-0.52, p<0.001)$ but the researchers accept them as separate constructs since they are conceptually distinct constructs. The disorientation factor structure consists of seven items with Cronbach's alpha of 0.89 , and the overall reliability of the scale is reported to be 0.87 .

A confirmatory factor analysis was conducted to test whether the original scale would yield similar results with PDS-Turkish (PDS-TR). For the confirmatory factor analysis, 216 undergraduate students (Female=174, Male= 42) from two departments (Psychology: Female=96, Male=12 and Computer \& IT: Female=78, Male=30) at a university voluntarily participated in this study. Participants were aged between 17 and $24(M=20.3, S D=1.44)$ with no reported psychiatric or neurological disorders; their mother tongue was Turkish.

Two different models (one with a single and one with a two-factor structure) have been tested. The two-factor model with a uni-dimensional nature yielded better fit values for the scale $(X 2 / d f=.29$, AGFI=0.87, NFI= .90, NNFI=.91, $\mathrm{CFI}=.93, \mathrm{GFI}=.92, \mathrm{RMSEA}=0.078$ ). The unstandardized parameter values obtained from the estimated two-factor structure model are presented in Figure 1 . The correlation coefficient between ease of use (EOU) and disorientation (DO) sub-constructs is found 
to be $.63(p<0.001)$, which is parallel to Ahuja and Webster's (2001) results. Since seven PDS items load highly on one factor, we conducted the second study with seven-item sub-factor to elicit readers' levels of perceived disorientation. Seven-item measure of disorientation scale in PDS-TR had Cronbach's alpha of 0.84 .

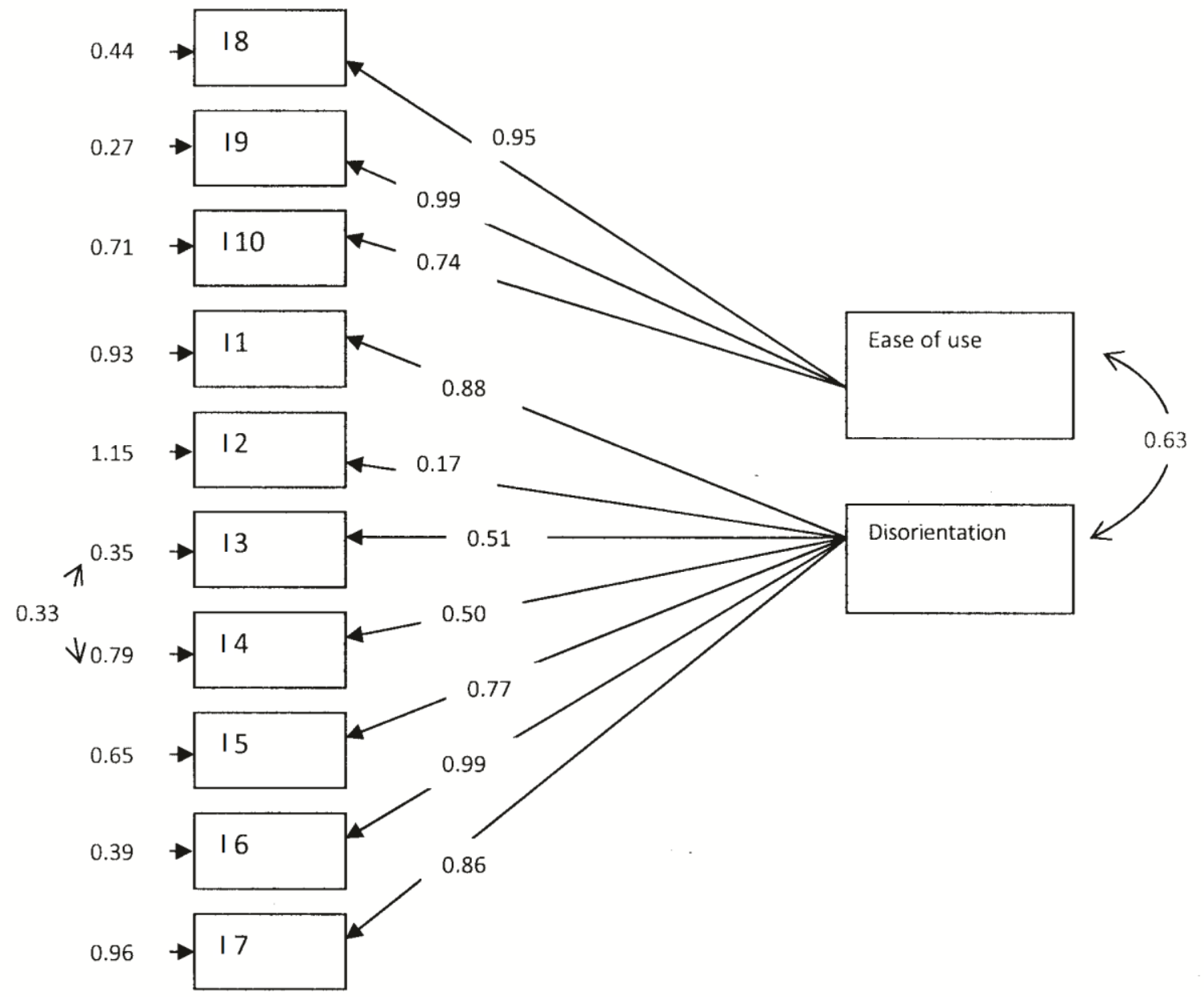

Figure 1. Confirmatory Factor Analysis Results

\section{Data Collection Procedures}

The experiment consisted of three sequential phases: Study phase, distractor task phase, and test phase. In the following section, these processes are described in detail.

\section{Study Phase}

In the study phase, the task was to read the materials (included target words) until the participants felt they comprehended the story and believed it was ended. A story with a total of 18 pages has been written by the researchers where two to four words have been hyperlinked for readers to 
choose per each page and readers are provided "I finished reading" link available at the bottom of each individual page and readers were requested to click on it as they thought they completed reading.

For the reading task, two types of hypertext structure were designed: Hierarchical with a left-side navigation menu and non-hierarchical without a navigation menu. Hierarchical and nonhierarchical hypertext structures included a reading passage (hyper) linked with two presentation types: Verbal or pictorial links. These hyperlinks were available for readers in either hierarchical (with a left-side navigation menu) or non-hierarchical (without a navigation menu) hypertext structure. In hierarchical hypertext environment, readers were given all the words in a menu on the left side, from which they could click on to continue reading (See Figure 2a). In non-hierarchical hypertext structure, readers were not provided this menu and were instructed to click on the hyperlinks embedded in the reading passage (See Figure 2b). Each presentation type had verbal (text-only) and pictorial (picture-only) types of media as hyperlinks (see Figures $3 \mathrm{a}, 3 \mathrm{~b}$ respectively) in each hypertext structure. Depending on their assigned group, readers navigated along these pages to complete their reading task.

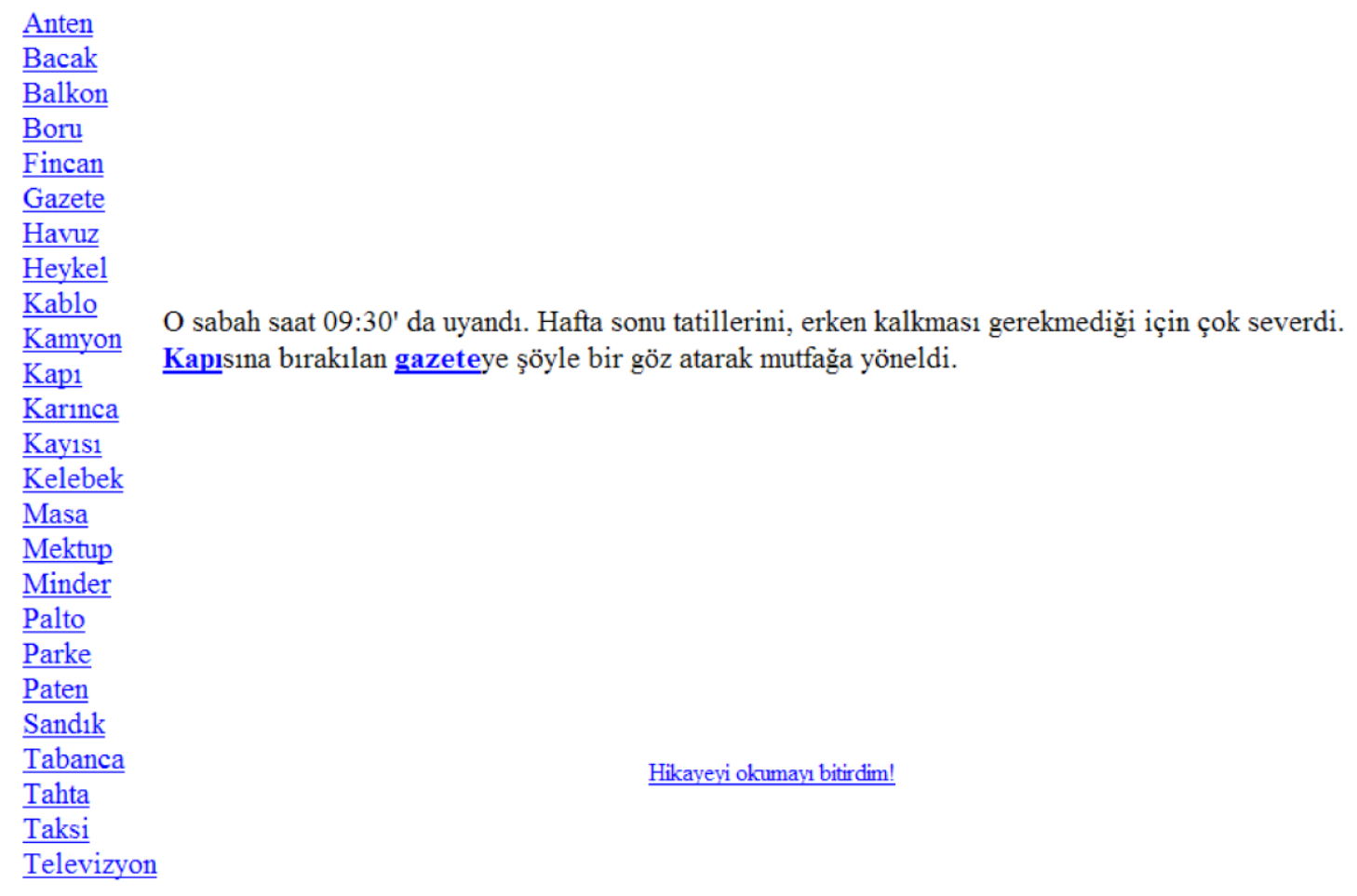

Figure 2a. A Sample Screenshot from Verbal Type of Media in Hierarchical Hypertext Structure 
O sabah saat 09:30' da uyandi. Hafta sonu tatillerini, erken kalkması gerekmediği için çok severdi. Kapısına bırakılan gazeteye şöyle bir göz atarak mutfağa yöneldi.

Hikayeyi okumayı bitirdim!

Figure 2b. A Sample Screenshot from Verbal Type of Media in Networked Hypertext

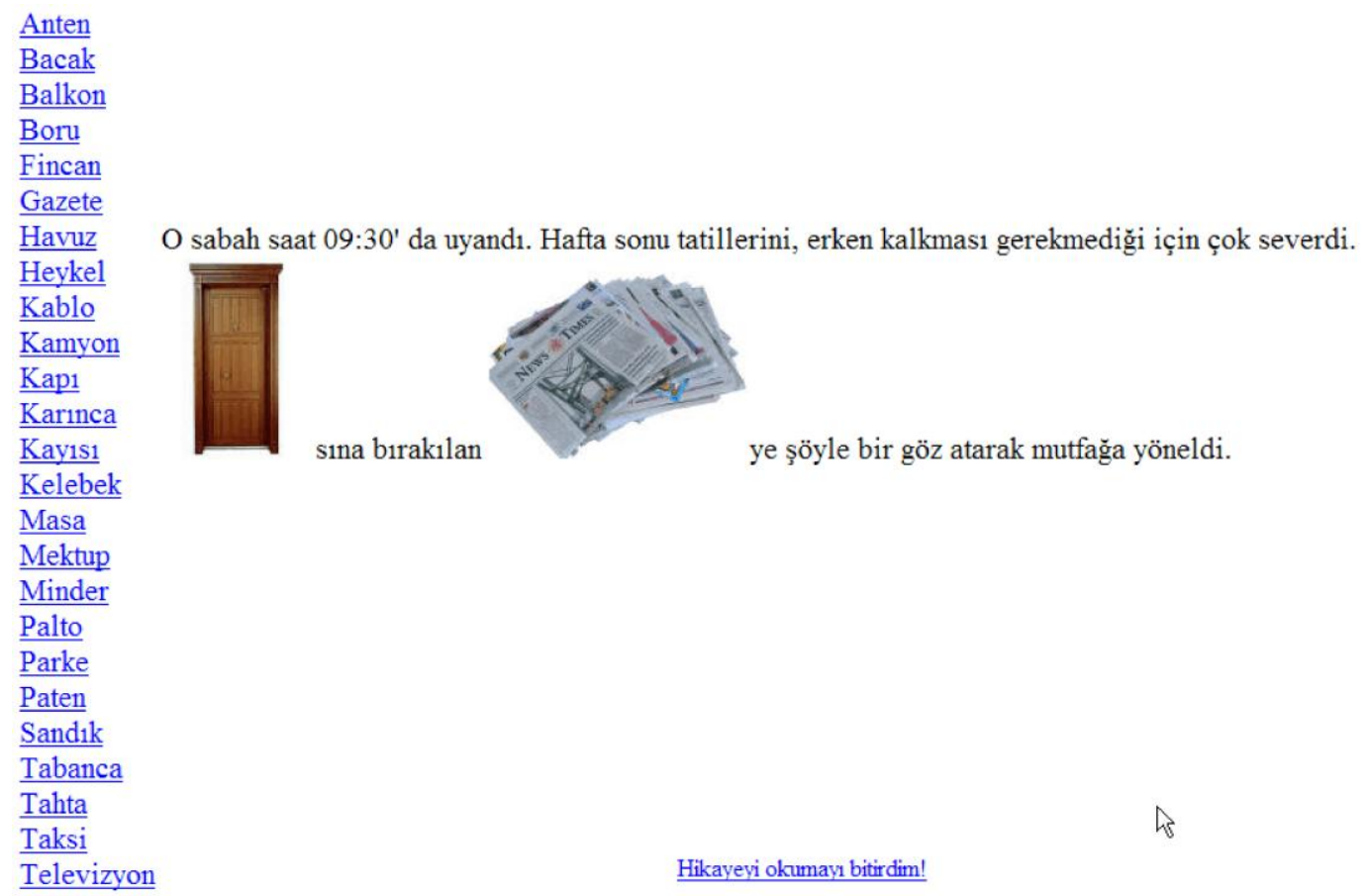

Figure 3a. A Sample Screenshot from Pictorial Type of Media in Hierarchical Hypertext Structure 
O sabah saat 09:30' da uyandı. Hafta sonu tatillerini, erken kalkması gerekmediği için çok severdi.

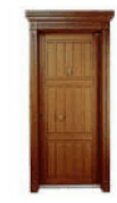

sina birakilan

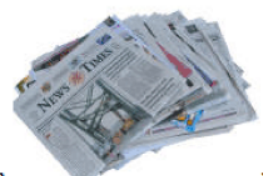

ye şöyle bir göz atarak mutfağa yöneldi.

Hikaveyi okumays bitirdim!

Figure 3b. A Sample Screenshot from Pictorial Type of Media in Networked Hypertext Structure

The reading task for readers was given either explicitly or implicitly. In the implicit group, readers were requested to complete the reading on their own pace whereas in the explicit one, readers were informed that they would be requested to remember the embedded (or hyperlinked) words they visited during their reading. No time limit was set to complete the reading task but was recorded for each reader.

\section{Distractor Task Phase}

In order to clear memorization of the task to be measured, a distractor task was designed. After the study phase, participants in both groups were invited to the distractor phase in which they were asked to complete a list of partially written names and last names of 20 famous artists in the target culture, as many as they could remember. This list obtained during the distractor phase was not scored. Finally, in the test phase -which will be described in brief below-, participants were given a WSC test in which they were asked to complete a word stem composed of the first three letters with the first word that came in to their minds. The participants recorded answers on a test form. During this session, participants were also asked to complete the perceived disorientation scale before leaving.

\section{Test Phase}

Two verbal material lists were utilized from a list of Vocabulary Norms prepared for target language (Tekcan \& Goz, 2005). The list included 25 studied and 25 non-studied concrete words (a total of 50 words). The first material list, studied words (target), were presented on the screen of a 15.4 inch 
PC, on a light gray background, and with letters in 'Arial' font and black color and all in the upper case for readers at the study stage. As a distraction task, 15 simple mathematical operations requiring the four arithmetic operations were used. At the test stage of the research, selected from the same word list 25 concrete-previously studied (target) and concrete-previously non-studied word lists comprising a total of 50 words were used.

Two methods are used to experimentally reveal implicit and explicit memory performances in the literature. The first method consisted of assigning participants to separate tasks that are assumed to represent implicit and explicit memory (Anooshian, 1999; Fleischman et al., 2005; Kim et al., 2005; Pauli, Dengler, \& Wiedemann, 2004). The second method consisted of carrying out the same task under different instructions (Goshen-Gottstein \& Kempinsky, 2001; Hamilton \& Rajaram, 2001; Pilotti, Meade, \& Gallo, 2003). In this study, the latter method was preferred and administered.

Participants were informed about the study and assigned randomly to either hierarchical with a left-side navigation menu or non-hierarchical -without a menu- condition in a silent computer laboratory. As readers completed reading, they were asked to rate their perceived levels of disorientation in PDS-TR. To ensure that participants responded concerning the specific web site they read, they were instructed both in oral and written statement as: "Please think about the web site you just finished (browsed for) reading. Then, read the following statements and rate them according to this particular web site you just completed."

\section{Data Analysis}

Data were analyzed by $2 \times 2 \times 2$ factorial MANCOVA. Hypertext structure, instruction type and presentation type were manipulated as between subjects variables on each dependent variable (WSC and PDS-TR), taking total reading time as a covariate.

\section{Results}

\section{Initial Analyses}

In all cases, tests for the equality of variances, covariance matrices, error variances, and the correlation matrix between the dependent variables - perceived disorientation levels and their implicit and explicit memory performances- in MANCOVA were tested before carrying out the statistical analyses described later. In order to ensure the equality of groups in terms of their short term memory spans, a $2 \times 2 \times 2$ factorial ANOVA analysis was run. Finally, participants' total reading time was compared across groups to observe whether time had an effect on the dependent variables.

In order to test the equality of covariance matrices across groups, Box's $M$ test was run. Results showed no violation of homogeneity of variance-covariance matrices (Box's $M=30,94, p=0.13$ ). Moreover, homogeneity of variance was checked by examining the result of Levene's Test of Equality of Error Variances. 
According to the ANOVA results, there was found no significant main effect of instruction type, hypertext structure and presentation type variables on VADS-B scores [sequentially; $(F(1,72)=$ 2.20, $p=.14 ; F(1,72)=0.16, p=.69 ; F(1,72)=0.06, p=.80)$ ]. Similarly, there was no significant interaction effect between instruction type and hypertext structure, instruction type and presentation type, hypertext structure and presentation type, instruction type, hypertext structure and presentation type [sequentially; $(F(1,72)=1.10, p=.30 ; F(1,72)=2.65, p=.11 ; F(1,72)=2.20$, $p=.14 ; F(1,72)=0.16, p=.69)]$. Thus, differences in participants' short term memory spans could be considered similar.

In order to increase the power of between group comparisons and reduce error variance (e.g., Fleiss, 1986; Frison \& Pocock, 1992), covariance analysis was applied. To select which variables to consider as covariates, the effects of hypertext structure, presentation type, and instruction type on readers' total reading time scores were examined. ANCOVA results yielded no significant main effect of hypertext structure and instruction type on readers' total reading time scores [sequentially; $(F(1,72=2.48, p=.11)(F(1,72)=0.47, p=.49)]$. However, there was a main effect of presentation type $(F(1,72=14.25, p=.000)$. Moreover, there was no significant interaction effect between the instruction type $\mathrm{x}$ hypertext structure, instruction type $\mathrm{x}$ hypertext structure $\mathrm{x}$ presentation type on total reading time scores [sequentially; $(F(1,72)=0.14, p=.70) ;(F(1,72)=$ $.47, p=.49)$ ]. However, there was a significant interaction effect between hypertext structure $x$ presentation type and instruction type $x$ presentation type on total reading time scores [sequentially; $(F(1,72=9.27, p=.003) ;(F(1,72)=16.4, p=.000)$ ].

The two significant interaction effects were analyzed using a simple main effects analysis. Hypertext structure and presentation type interaction effects were found to be significant on total time scores. These result indicate that hypertext structure influenced participants' total time in reading in networked condition $(F(1,76)=19,76, p<.05)$, but not in hierarchical condition $(F(1,76)=.22, p<.05)$. For participants in the networked hypertext structure condition, total reading time scores was lower with the picture condition $(M=6.43, S E=0.56)$ than with the text condition $(\mathrm{M}=9.95, \mathrm{SE}=0.56, \mathrm{p}<.001)$. In regards to instruction type and presentation type, interaction effect is found to be significant. According to this result, it can said that instruction type influenced participants' total time under implicit instruction $(F(1,76)=27,57, p<.000)$ but not under explicit instruction $(F(1,76)=.19, p=.85)$. Also, simple main effect analysis revealed that for the participants in the implicit instruction type, total reading time scores was lower with picture condition $(\mathrm{M}=$ $5.59, \mathrm{SE}=0.54)$ than with text condition $(\mathrm{M}=9.62, \mathrm{SE}=0.54, \mathrm{p}=.000)$. Thus, total reading time was taken as a covariate in the further analyses.

\section{MANCOVA Results for WSC and PDS-TR Scores}

Descriptive statistics for HS, PT, and IT on WSC and PDS-TR scores in different experimental conditions are presented in Table 2. 
Table 2. Means and Standard Deviations of WSC and PDS-TR Scores on Experimental Conditions

\begin{tabular}{|c|c|c|c|c|c|}
\hline & & $\begin{array}{l}\text { Hierarchical } \\
(n=40)\end{array}$ & & $\begin{array}{l}\text { Networked } \\
(n=40)\end{array}$ & \\
\hline & & Verbal & Pictorial & Verbal & Pictorial \\
\hline \multirow{2}{*}{ WSC } & Implicit & $\begin{array}{l}15.60(4.95) \\
(n=10)\end{array}$ & $\begin{array}{l}15.50(6.22) \\
(n=10)\end{array}$ & $\begin{array}{l}18.00(4.67) \\
(n=10)\end{array}$ & $\begin{array}{l}11.40(4.50) \\
(n=10)\end{array}$ \\
\hline & Explicit & $\begin{array}{l}22.90(2.42) \\
(n=10)\end{array}$ & $\begin{array}{l}17.50(6.87) \\
(n=10)\end{array}$ & $\begin{array}{l}24.00(5.77) \\
(n=10)\end{array}$ & $\begin{array}{l}13.80(4.80) \\
(n=10)\end{array}$ \\
\hline \multirow{2}{*}{ PSD-TR } & Implicit & $\begin{array}{l}2.91(0.81) \\
(n=10)\end{array}$ & $\begin{array}{l}3.75(0.45) \\
(n=10)\end{array}$ & $\begin{array}{l}3.5(0.43) \\
(n=10)\end{array}$ & $\begin{array}{l}3.29(1.06) \\
(n=10)\end{array}$ \\
\hline & Explicit & $\begin{array}{l}3.27(0.62) \\
(n=10)\end{array}$ & $\begin{array}{l}3.44(0.76) \\
(n=10)\end{array}$ & $\begin{array}{l}3.42(0.56) \\
(n=10)\end{array}$ & $\begin{array}{l}3.24(0.77) \\
(n=10)\end{array}$ \\
\hline
\end{tabular}

WSC: Word stem completion scores, PDS-TR: Perceived Disorientation Scores-Turkish

MANCOVA analyzes yielded that both instruction type $(F(1,71)=13.85, p=.000)$ and presentation type $(F(1,71)=15.54, p=.000)$ were significant main effect on WSC. However, there was no significant main effect of hypertext structure observed for neither WSC nor PDS-TR scores. Those in the explicit instruction group recalled more words $(M=19.55, S D=6.5)$ than did the implicit instruction group $(M=15.12, S D=5.4)$. In addition, those in the verbal presentation group ( $M=$ $20.12 S D=5.65)$ outperformed those in pictorial group $(M=14.55, S D=5.91)$. No other interaction effects were found significant on WSC score. The interaction effect of hypertext structure and presentation type is significant on participants' PDS-TR $(F(1,71)=5.00, p=.028)$. Those in the hierarchical structure with pictorial condition $(\mathrm{M}=3.58, \mathrm{SE}=.16)$ and networked structure with verbal condition $(M=3.5, S E=.18)$ perceived more disorientation than those in hierarchical with verbal condition $(M=3.08, S E=.16)$ and networked with pictorial conditions $(M=3.24, S E=.17)$ (See Figures $4 a$ and $4 b$ ). 


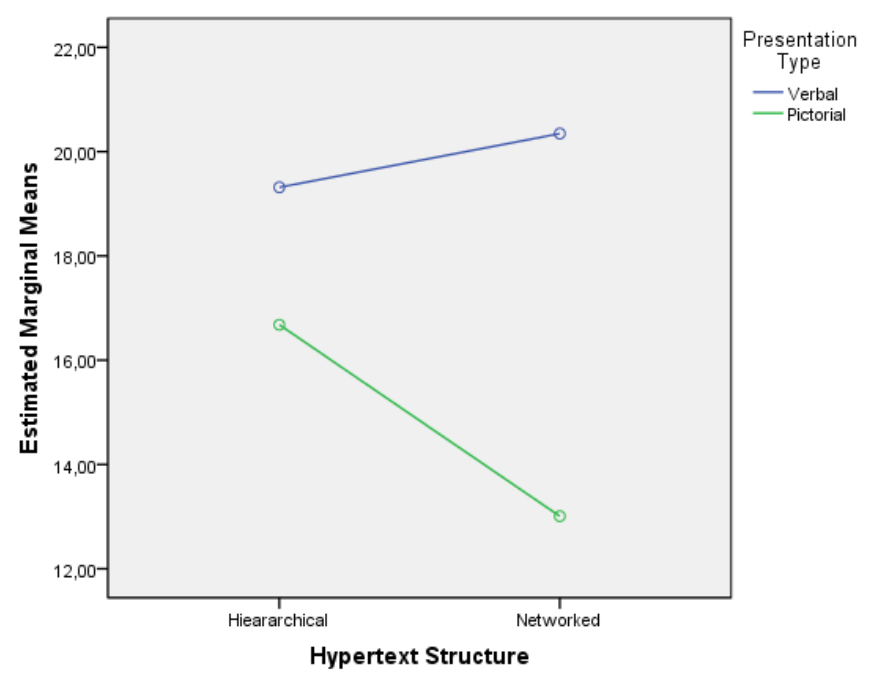

Figure 4a. The interaction effect between Hypertext Structure and Presentation Type on WSC Scores

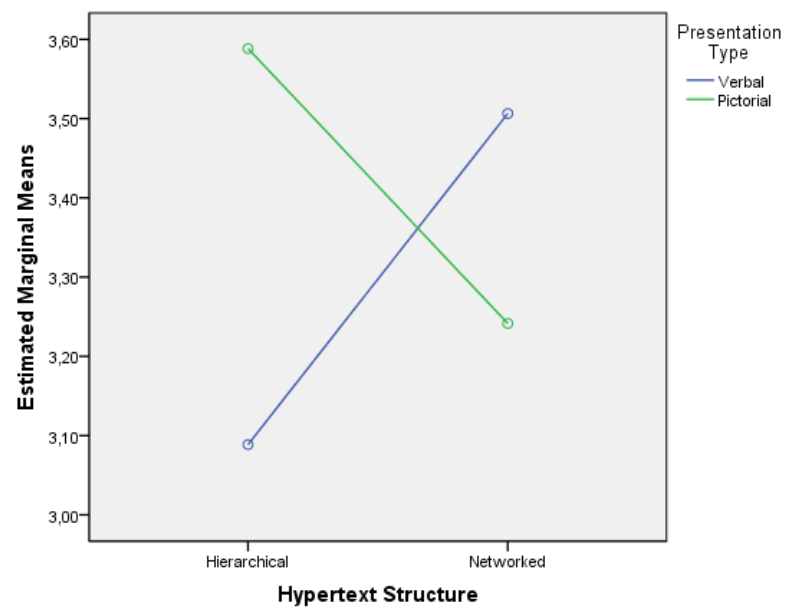

Figure 4b. The interaction effect between Hypertext Structure and Presentation Type on PDS-TR Scores 


\section{Discussion and Conclusion}

This study was carried out with participants -equal in their short term memory capacities- to explore the effects of the hypertext structure (hierarchical vs. networked), instruction type (implicit vs. explicit), and presentation type (verbal vs. pictorial) on their implicit and explicit memory performances by WSC task, and their perceived disorientation levels.

The findings indicated that WSC scores were affected by presentation and instruction types. Moreover, perceived disorientation was not affected by presentation and instruction types. In addition, hypertext structure did not affect either the WSC or PDS-TR scores. These findings indicate that (a) depending on how content is presented and structured, total time in reading would be affected, and (b) WSC scores change according to presentation and the instruction type. Readers in verbal condition had higher WSC scores under explicit instructions than implicit one. Moreover, readers spent more time for reading when the presentation type is verbal. This finding confirms DeStefano and LeFevre's (2007) study in that visual presentation had an interfering effect on overall recall performance.

Although the main effects of presentation and instruction type are found to be statistically significant, none of the other interaction effects was significant on participants' WSC scores. This finding partially challenges De Stefano et al.'s (2007) conclusion in that memory capacity had a modulating effect on the hypertext structure. According to De Stefano et al. (2007) memory capacity was modulated by the hypertext structure. If short-term memory capacities of readers are not controlled, the modulating effect had disappeared. Further studies are needed to explore short-term memory span of hypertext readers. Moreover, the links in this study were available based on the selected most frequently used Vocabulary Norms list for the target language. Further studies with less frequently used words could be studied with different hypertext structures to observe if these findings could be generalized.

Oulasvirta et al. (2005) asserted that implicit expectations guided readers' attention in accessing the locations of links. They go further to add that it takes deep processing for readers to recall these locations consciously. The findings of this study extend these findings by clarifying the fact that main effects were observed in implicit and explicit instructions. Further studies are needed to investigate how other presentation types (e.g., verbal, pictorial and verbal+pictorial) affect WSC scores. It should be noted that the reading tasks in this study did not require readers to read for surface and/or deep levels of processing. Readers were simply requested to follow the links until they thought they grasped the meaning of the story and felt the story was over. One can speculate that some readers could have done surface reading whereas the others had a deep level of processing. Thus, it can further be explored how WSC scores could change when the levels of processing were manipulated. Further studies are needed to explore levels of processing as an independent variable.

The interaction effect of hypertext structure and presentation type was statistically significant on PDS-TR scores. Readers felt more disorientation when the structure is hierarchical and the presentation is verbal; whereas, networked condition did not affect readers perceived disorientation score. These findings extend Amadieu et al.'s (2009) study in that, in addition to readers' prior knowledge and concept map structures, hypertext structure together with 
presentation type might influence readers' perceived disorientation. When designing e-learning environments and content for learners, instructional designers could be cautious about using hierarchical design with verbal content.

Finally, short-term memory, both in implicit and explicit conditions, functions independently from hypertext structure; yet, it is affected by the interaction of hypertext structure and presentation types. Instructional designers and e-learning providers might benefit from presenting their content matter by taking readers' changeable total reading times into account along with presentation and instruction types when designing hypertext environments. More intervention research is needed to explore the effectiveness of these variables on hypertext reading and learning from hypertext research in various content areas such as learning novel topics across well-defined and ill-defined areas.

\section{References}

Altun, A. (2000). Patterns in cognitive processes and strategies in hypertext reading: A case study of two experienced computer users. Journal of Educational Hypermedia and Multimedia, 9, 3248.

Altun, A. (2003). Understanding hypertext in the context of reading on the web: Language learners' experience. Current Issues in Education, 6(5). Available online at: http://cie.ed.asu.edu/ volume6/number9/

Ahuja, J. S. \& Webster, J. (2001). Perceived disorientation: An examination of a new measure to assess web design effectiveness. Interacting with Computers, 14 (1), 15-29.

Alomyan, H. (2004). Individual differences: Implications for web-based learning design. International Education, 4(4), 188-96.

Amadieu, F., van Gog, T., Paas, F., Tricot, A., \& Mariné, C. (2009). Effects of prior knowledge and concept-map structure on disorientation, cognitive load, and learning. Learning and Instruction, 19(5), 376-386.

Anooshian, L.J. (1999). Understanding age differences in memory: Disentangling conscious and unconscious processes. International Journal of Behavioral Development, 23(1), 1-18.

Boechler, P. M. (2001). How spatial is Hyperspace? Interacting with hypertext documents: Cognitive processes and concepts. Cyberpsychology and Behavior, 4(1), 23-46.

DeStefano D. \& LeFevre, J. (2007). Cognitive load in hypertext reading: A review. Computers in Human Behaviour, 23, 1616-1641.

Dillon A. (2000). Designing a Better Learning Environment with the Web: Problems and Prospects. Cyberpsychology and Behavior, 3(1), 97-101.

Dillon, A. \& Gabbard, R. (1998). Hypermedia as an educational technology: A review of the quantitative research literature on learner comprehension, control, and style. Review of Educational Research, 68(3), 322 -349. 
Edwards, D. M. \& Hardman, L. (1989). 'Lost in hyperspace': Cognitive mapping and navigation in a hypertext environment. In R. McAleese (Ed.), Hypertext: Theory into practice (pp.105-125). Norwood, NJ: ABLEX.

Fleischman, D. A., Wilson, R. S, Gabrieli, J. D. E., Schneider, J. A, Bienias, J. L., \& Bennett, D. A. (2005). Implicit memory and Alzheimer's disease. Brain, 128, 2006-2015.

Foss, C. L.(1989). Tools for reading and browsing hypertext. Information Processing and Management, 25, 407-18.

Gamberini, L. \& Bussolon, S. (2001). Human navigation in electronic environments. Cyberpsychology \& Behavior, 4(1), 57-65.

Goshen-Gottstein, Y. \& Kempinsky, H. (2001). Probing memory with conceptual cues at multiple retention intervals: A comparison of forgetting rates on implicit and explicit tests. Psychonomic Bulletin and Review, 8(1), 139-46.

Graf, P. \& Schacter, D. L. (1985). Implicit and explicit memory for new associations in normal and amnesic subjects. Journal of Experimental Psychology: Learning, Memory, \& Cognition, 11(3), 501-518.

Hamilton, M. \& Rajaram, S. (2001). The concreteness effect in implicit and explicit memory tests. Journal of Memory and Language, 44, 96-117.

Karakas, S. \& Yalin, A. (1995). Normative study of Visual Aural Digit Span Test Form-B on Turkish adolescents and adults (ages 13-54). Turkish Journal of Psychology, 10(34), 20-31.

Kim, H. \& Hirtle, S. C. (1995). Spatial metaphors and disorientation in hypertext browsing. Behaviour \& Information Technology, 14, 239-250.

Kim, M. S., Kim, Y. Y., Kim, F. N., Lee, K. J., Ha, T. H., \& Kwon, J. S. (2005). Implicit and explicit memory in patients with obsessive-compulsive disorder: An event-related potential study. Journal of Psychiatric Research, 40(6), 541-549.

Koppitz, E. M. (1977). The visual aural digit span test. New York: Grune and Stratton.

Light, L. L., Prull, M. W, LaVoie, D. J., \& Healy, M. R. (2000) Dual-process theories of memory in old age. In: T. J. Perfect and E. A. Maylor (Eds.), Models of cognitive aging: Debates in Psychology. London: Oxford University Press.

Markowitch, H. J. (2000). Memory and Amnesia. In M.M. Mesulam (Ed.), Principles of behavioral and cognitive neurology. New York: Oxford University Press.

McDonald, S. \& Stevenson, R. J. (1998). Effects of text structure and prior knowledge of the learner on navigation in hypertext, Human Factors, 40(1), 18-27.

Nielsen, J. (1990). Hypertext and hypermedia. San Diego, CA: Academic Press.

Nishimura, T. \& Takeda, M. (2000). The neural basis of perceptual and conceptual word priming: A PET study. Cortex, 36, 59-69.

Oulasvirta, A. (2004). Task demands and memory in web interaction: A levels of processing approach. Interacting with Computers, 16(2), 217-241. 
Oulasvirta, A., Kärkkäinen, L., \& Laarni, J. (2005). Expectations and memory in link search. Computers in Human Behavior, 21, 773-789.

Pauli, P., Dengler, W., \& Wiedemann, G. (2004). Implicit and explicit memory processes in panic patients as reflected in behavioral and electrophysiological measures. Journal of Behavior Therapy and Experimental Psychiatry, 36(2): 111-127.

Pilotti, M., Meade, M.L., \& Gallo, D.A. (2003). Implicit and explicit measures of memory for perceptual information in young adults, healthy older adults, and patients with Alzheimer's Disease. Experimental Aging Research, 29, 15-32.

Rasch, T. \& Schnotz, W. (2009). Interactive and non-interactive pictures in multimedia learning environments: Effects on learning outcomes and learning efficiency. Learning and Instruction, 19(5), 411-422.

Rouet, J. F. (2003). What was I looking for? The influence of task specificity and prior knowledge on students' search strategies in hypertext. Interacting with Computers, 15, 409-428.

Rouet, J.F. \& Levonen, J. (1996). Studying and learning with nonlinear documents: Empirical studies and their implications. In J. F. Rouet, J. J. Levonen, A. Dillon, and R. Spiro (Eds.). Hypertext and Cognition (pp.9-23). Mahvah, NJ: Lawrence Erlbaum.

Schacter, D. L. (1987). Implicit memory: History and current status. Journal of Experimental Psychology: Learning, Memory, \& Cognition, 13(3), 501-18.

Shapiro, A. \& Niederhauser, D. (2004). Learning from hypertext: Research issues and findings. In: D. $\mathrm{H}$. Jonassen (Ed.), Handbook of research on educational communications and technology (pp.605-620). Mahwah, NJ: Erlbaum.

Squire, L. R. (1992). Memory and the hippocampus: A synthesis from findings with rats, monkeys, and humans. Psychological Review, 99(2), 192-231.

Tekcan, A. I, and Goz, İ. (2005). Turkce kelime normlari (Turkish vocabulary norms). İstanbul: Bosphorus University Press.

Yasuno, F., Nishikawa, T., Tokunaga, H., Yoshiyama, K., Nakagawa, Y., Ikejiri, Y., Oku, N., Hashikawa. K., Tanabe, H., Shinozaki, K., Sugita, Y., Cress, U., \& Knabel, O. B. (2003). Previews in hypertexts: Effects on navigation and knowledge acquisition. Journal of Computer Assisted Learning, 19(4), 517-527.

Correspondence: Arif Altun, Professor, Department of Computer Education and Instructional Technologies, Faculty of Education, Hacettepe University, Ankara, Turkey 